RU Диминутив «потихоньку» в текстах параллельного корпуса. Часть 2

Сидорова Е. Ю.

Аннотация. Цель исследования - выявление особенностей употребления разговорного диминутива «потихоньку» в текстах переводов с английского языка на русский и с русского языка на английский, для чего проводится уточнение семантики «потихоньку» на основании данных параллельного корпуса. Научная новизна исследования заключается в том, что диминутив «потихоньку» впервые рассматривается с точки зрения лингвоспецифичности. В результате выделены и охарактеризованы особенности контекстуального употребления наречия «потихоньку» в текстах параллельного корпуса, которые рассматриваются для уточнения семантической природы диминутива «потихоньку». На основании проведенного исследования рассматривается вопрос о возможности считать наречие «потихоньку» лингвоспецифичной единицей.

\title{
EN Diminutive «Потихоньку» in the Texts of Parallel Corpus
}

\author{
Sidorova E. Y.
}

Abstract. The aim of the study is to identify the features of using the colloquial diminutive потихоньку in the texts of translations from English into Russian and from Russian into English, to refine the semantics on the basis of data from the parallel corpus. The scientific originality of the research lies in the fact that the diminutive потихоньку is considered for the first time from the point of view of linguistic specificity. As a result, the features of the contextual use of the adverb потихоньку in the texts of the parallel corpus are highlighted and characterized, which are considered to clarify the semantic nature of the diminutive. On the basis of the study, the question of the possibility of describing the adverb as a lingo-specific unit is considered.

\section{Введение}

Русские диминутивы представляют особый интерес для научного изучения и до сих пор вызывают немало вопросов и с точки зрения лингвистики (см., например, работы И. В. Фуфаевой (2017), М. Д. Воейковой (2020), Н. А. Николиной (2020)), и с точки зрения лингводидактики (см. работы Л. А. Шлыковой, В. Эльвии (2012), Л. В. Чевардиной (2018)). Диминутивы обладают сложной и насыщенной семантической природой, многие из них довольно часто употребляются в разговорной речи и стилистически маркированы. Данная статья посвящена изучению семантики диминутивного наречия потихоньку, а также рассмотрению потенциальной возможности отнести данную лексему к лингвоспецифичным единицам.

Понятие лингвоспецифичности лексической единицы означает, что ее семантика несет в себе особенные черты национального языка (и - шире - лингвокультуры), которые являются важными для носителей языка и которые отличаются от того или иного иностранного языка, что можно выявить путем анализа текстов перевода. Теоретической базой исследования послужили труды Анны А. Зализняк (2015), А. Д. Шмелева (2015) и др., работающих над исследованием лингвоспецифичных единиц с помощью корпусов, а также труды В. Д. Девкина (1979), Ю. М. Скребнева (1985), В. К. Харченко (2016) и др., посвященные особенностям разговорной речи.

Статья является продолжением исследования, первая часть которого описана в работе «Диминутив “потихоньку” в текстах параллельного корпуса. Часть 1». В первой части рассматриваются результаты корпусного исследования разговорного наречия потихоньку на материале англо-русского корпуса (Национальный корпус русского языка, 2021), где в оригинальных английских текстах представлены наречия, а также прилагательные и местоимения, которые послужили стимулом перевода для слова потихоньку в русских текстахпереводах. В данной статье рассмотрим более сложные и неоднозначные случаи перевода.

Актуальность исследования обусловлена его включенностью в теоретическое русло исследований семантики разговорных единиц, а также в русло современных исследований лингвоспецифичности лексических единиц. Актуальность изучения разговорной речи и отдельных разговорных лексем обусловлена прежде всего

Научная статья (original research article) | https://doi.org/10.30853/phil210567

(c) 2021 Авторы. ООО Издательство «Грамота» (๔ 2021 The Authors. GRAMOTA Publishers). Открытый доступ предоставляется на условиях лицензии СС BY 4.0 (open access article under the CC BY 4.0 license): https://creativecommons.org/licenses/by/4.0/ 
изменчивостью материала исследования, происходящими изменениями в значении слов, не всегда фиксируемыми в словарях и нуждающимися в фиксации. Корпусные исследования помогают рассмотреть особенности употребления слова на широком материале как письменных текстов, так и устной речи. Кроме того, особый интерес представляет изучение разговорных единиц с точки зрения лингвокультурологии. В русском языке есть широкие возможности для образования диминутивов и от существительных, и от прилагательных, и от наречий. Некоторые из диминутивов частотны в разговорной речи, как, например, наречие потихоньку. Представляет особый интерес рассмотрение вопроса о возможности считать диминутив потихоньку лингвоспецифичной единицей.

В данной работе поставлены задачи: 1) отобрать тексты переводов в параллельном англо-русском корпусе и классифицировать стимулы перевода в соответствии с частеречным принципом и лексико-семантическими группами (там, где возможно их выделение); 2) определить значение наречия потихоньку в отобранных примерах и сравнить его со значением английских стимулов перевода; 3) выполнить те же задачи на материале русско-английского корпуса и сравнить результаты, выявленные при работе с англо-русским и с русскоанглийским корпусами; 4) сопоставить полученные данные с основными критериями лингвоспецифичности единиц, выделенных Анной А. Зализняк. В работе использованы методы корпусной лингвистики, контекстологический анализ, метод компонентного анализа лексического значения и метод наблюдения.

Практическая значимость исследования заключается в возможности использовать полученные данные в курсах по стилистике и переводу, а также при подготовке учебных материалов и пособий.

\section{Основная часть}

Анализ примеров употребления потихоньку в текстах параллельного корпуса позволил выявить несколько групп примеров, характеризующих особенности употребления потихоньку в текстах переводов. Первая группа примеров представлена текстами, в которых стимулами перевода являются английские глаголы, которые описывают движение или перемещение с дополнительными оттенками, которые коррелируют с семантикой наречия потихоньку.

1. Sneak.

(1) “Then, later that night," Edgar continued, “while you were sleeping, he snuck out and drove up into the hills and dumped the body” [Michael Connelly. City Of Bones (2002) | Майкл Коннели. Город костей (Д. Вознякевич, 2006)].

- Позднее, - продолжил Эдгар, - когда вы спали, он вышел потихоньку, поехал к холму и бросил тело там [Майкл Коннели. Город костей (Д. Вознякевич, 2006)].

Глагол sneak into / out / around, etc., согласно Кэмбриджскому словарю (2021) (здесь и далее приводятся толкования английских лексем по данному источнику), имеет значение 'to go somewhere quietly because you do not want anyone to hear you' (‘прокрадываться’). В данном переводе мы видим словосочетание выйти потихоньку. Здесь можно заметить и сему 'тихо’, и сему 'украдкой’. В результатах поиска этот глагол трижды стал стимулом перевода для лексической единицы потихоньку.

2. Smuggle.

(2) The children knew that the Quagmire triplets were in grave danger, and that using Violet's invention to melt the bars of the cage was the only way that their friends could escape before Gunther hid them inside one of the items of the In Auction, and smuggled them out of the city [Lemony Snicket. The Erzatz Elevator (2001) | Лемони Сникет. Липовый лифт (А. Ставиская, 2005)].

Дети понимали, что Квегмайрам грозит страшная опасность и единственный способ помочь им это распилить прутья клетки, применив изобретение Вайолет. Но сделать это надо до того, как Гюнтер упрячет Дункана и Айседору в один из лотов Модного Аукциона, а потом потихоньку увезет из города [Лемони Сникет. Липовый лифт (А. Ставиская, 2005)].

Глагол smuggle имеет значение 'to take something into or out of a place in an illegal or secret way' ('провозить контрабандой, тайно проносить’). Здесь переводчик выбрал вариант перевода потихоньку увезти. Появляется сема 'тайно, украдкой'.

3. Inch.

(3) Apparently sensing Langdon's stymie, Vittoria turned to the docent, who was now inching away. She grabbed his arm and reeled him in. "I need a tomb. Designed by Raphael" [Dan Brown. Angels and Demons (2000) | Дэн Браун. Ангелы и демоны (Г. Косов, 2004)].

Почувствовав смятение американца, девушка повернулась к гиду, который потихоньку отодвигался от странной парочки. Она схватила его за рукав и, притянув к себе, сказала:

- Мне нужно найти гробницу, спроектированную и сооруженную Рафаэлем [Дэн Браун. Ангелы и демоны (Г. Косов, 2004)].

Согласно Кэмбриджскому словарю (2021), глагол inch означает 'to move somewhere slowly or by very small amounts' ('осторожно двигаться ближе/вперед/вверх и т.д.'). В данном контексте inch away было переведено как потихоньку отодвигаться, при этом у наречия потихоньку актуализируется лексико-семантический вариант 'медленно, не торопясь', можно также отметить компонент 'чтобы его движение не было замечено / не было слишком явным'.

4. Steal away / in / out, etc.

(4) You don't think he could be stealing away and leaving us tonight, do you? [Clive Staples Lewis. The Chronicles of Narnia. The Lion, the Witch and the Wardrobe (1950) | Клайв Стейплз Льюис. Хроники Нарнии. Лев, колдунья и платяной шкаф (Г. А. Островская, 1991)]. 
Как ты думаешь, он не хочет потихоньку уйти сегодня ночью и оставить нас одних? [Клайв Стейплз Льюис. Хроники Нарнии. Лев, колдунья и платяной шкаф (Г. А. Островская, 1991)].

Глагол steal away / in / out означает 'to move somewhere quietly and secretly'. В данном контексте steal away перевели как потихоньку уйти, при этом актуализируется значение наречия потихоньку 'незаметно, тайно, украдкой’.

5. Sidle up.

(5) He sent his research team to New York's train stations and betting shops, where they sidled up to the waiting customers and inserted themselves between the third and fourth person - then stayed for around a minute before departing. [David Robson. We hate to admit it but brits aren't the best at queuing (www.bbc.com) (2017) | Poмантика британских очередей: как всех правильно построить (bbc.com/russian)].

Ученый отправил группу исследователей на станции подземки и в букмекерские конторы Нью-Йорка. Задачей было потихоньку подойти к ожидающим клиентам, втиснуться в очередь между третьим и четвертым человеком, простоять там около минуты и затем уйти [Романтика британских очередей: как всех правильно построить (bbc.com/russian)].

Глагол sidle along / over / up имеет значение ‘пробираться украдкой вдоль / к и т.д.’, выбор наречия потихоньку в русском переводе (потихоньку подойти) соответствует семантическому компоненту 'украдкой’.

6. Slip и slip away / out / through, etc.

(6) She would slip out some night when it was too late and all hope had been abandoned - when exposure was near - and the next day they would find her. [Theodore Dreiser. The “Genius”, book I-II (1915) | Теодор Драйзер. «Гений» (ч. 1-2) (М. Волосов, 1930)].

Она просто выйдет как-нибудь ночью потихоньку из дому - если окажется, что больше не на что надеяться, что позора не скроешь, - и на другой день найдут ее труп [Теодор Драйзер. «Гений» (ч. 1-2) (М. Волосов, 1930)].

Фразовый глагол slip away / out / through означает 'незаметно ускользнуть', семантический компонент 'незаметно’ соответствует одному из значений потихоньку.

Интересны примеры с глаголом slip в значении 'засовывать / просовывать что-либо куда-либо, сунуть'. Вероятно, семантический компонент ‘украдкой’ характерен для английского глагола slip не только как фразового глагола движения, но и в данном случае:

(7) Well, she had a second glass and then we went through to the other room where I'd slipped my present in her place, which she saw at once [John Fowles. The Collector (1963) | Джон Фаулз. Коллекционер (И. Бессмертная, 1991)].

Ну, она выпила еще бокал вина, и мы перешли в другую комнату, где я потихоньку положил свой подарок рядом с ее прибором, только она сразу заметила [Джон Фаулз. Коллекционер (И. Бессмертная, 1991)].

7. Creep back.

(8) At the faint echo of passion in his voice, pleasure and excitement crept back into her [Margaret Mitchell. Gone with the Wind, Part 2 (1936) | Маргарет Митчелл. Унесённые ветром, ч. 2 (Т. Кудрявцева, 1982)].

Уловив слабый отголосок страсти в его голосе, она почувствовала, как радость и волнение потихоньку наполняют ее [Маргарет Митчелл. Унесённые ветром, ч. 2 (Т. Кудрявцева, 1982)].

У глагола creep across / in / into есть значение 'to gradually start to exist or appear' ('постепенно возникать'), т.е. в данном случае потихоньку, очевидно, использовался для передачи значения 'постепенно'.

8. Saunter into / over / through, etc.

(9) Then they sauntered over to my house and sat on the steps for half an hour, while at her request I remained watchfully in the garden [F. Scott Fitzgerald. The Great Gatsby (1925) | Ф. Скотт Фицджеральд. Великий Гэтсби (Е. Калашникова, 1965)].

Потом они потихоньку перебрались на мой участок и с полчаса сидели вдвоем на ступеньках крыльца, а я в это время, по просьбе Дэзи, сторожил в саду [Ф. Скотт Фицджеральд. Великий Гэтсби (Е. Калашникова, 1965)].

Глагол saunter into / over / through имеет значение 'to walk somewhere in a slow and relaxed way' ('двигаться неторопливо, прогуливаться’). Потихоньку здесь передает значение 'неторопливо’.

9. Stalk off.

(10) He stalked off by himself and was soon lost to sight behind a slight rise in the ground [Douglas Adams. The Hitchhiker's Guide to the Galaxy (1978-1979) | Дуглас Адамс. Путеводитель хитч-хайкера по Галактике (Вадим Филиппов, 1995-1997)].

Он потихоньку отошел в сторону и скоро скрылся за небольшой возвышенностью [Дуглас Адамс. Путеводитель хитч-хайкера по Галактике (Вадим Филиппов, 1995-1997)].

Глагол stalk off имеет значение 'to walk in an angry or proud way', что можно перевести как уходить в раздражении или торжественно / горделиво удаляться, то есть присутствует эмоциональная окраска, сопровождающая действие по глаголу уходить. В следующем примере он был переведен так: потихоньку отойти в сторону. Какие именно эмоции сопровождали это действие - неизвестно, эмоциональная окраска здесь скрыта, наречие потихоньку, видимо, передает неспешность действия, в которой могут быть скрыты и эмоции.

Вторая группа примеров представлена контекстами, в которых стимулом перевода послужили слова (как правило, глаголы), указывающие на начало действия. Например:

(11) "You wouldn't need to," said Ford. "They've got as much sex appeal as a road accident. No, don't move," he added as Arthur began to uncurl himself, "you'd better be prepared for the jump into hyperspace. It's unpleasantly like being drunk” [Douglas Adams. The Hitchhiker's Guide to the Galaxy (1978-1979) | Дуглас Адамс. Путеводитель хитч-хайкера по Галактике (Вадим Филиппов, 1995-1997)].

- $\quad$ Я думаю, она сама бы сообразила. С любой точки зрения, и с половой тоже, вогены страшнее звездной войны. Не двигайся, - добавил Форд, увидев, что Артур потихоньку разворачивается. - Лучше приготовься 
к гиперпереходу. На организм он действует, как крупная пьянка [Дуглас Адамс. Путеводитель хитч-хайкера по Галактике (Вадим Филиппов, 1995-1997)].

В данном примере в английском тексте указано на начало действия с помощью глагола begin (began to uncurl himself - дословно начал разворачиваться), что было переведено с помощью глагола несовершенного вида и наречия потихоньку.

Рассмотрим следующий контекст, демонстрирующий оттенок начала действия:

(12) I knew she'd follow me, so I started walking downtown toward the zoo, on the park side of the street, and she started walking downtown on the other goddam side of the street [J. D. Salinger. The Catcher in the Rye (1951)। Дж. Д. Сэлинджер. Над пропастью во ржи (Р. Райт-Ковалёва, 1965)].

Я знал, что она-то за мной пойдет как миленькая, и я потихоньку направился к зоопарку по одной стороне улицы, а она пошла туда же, только по другой стороне [Дж. Д. Сэлинджер. Над пропастью во ржи (Р. Райт-Ковалёва, 1965)].

Фраза с глаголом start ('начать') I started walking downtown toward the zoо переведена с использованием потихоньку: я потихоньку направился к зоопарку.

Особую связь семантики лексемы потихоньку и компонента ‘начало действия’ подтверждают статистические данные о сочетаемостных характеристиках потихоньку. Результаты поиска в основном корпусе русского языка по биграммам демонстрируют, что после потихоньку наиболее частотный глагол начал, за ним следуют формы стал, стали, начинает. А анализ сочетаемости глаголов, стоящих перед потихоньку, в поиске по биграммам показал, что наиболее частотны следующие формы (в порядке уменьшения частотности): стал, начал, стали, начали, стала, начала, начинает. Существует взаимосвязь значения слова и его сочетаемостных свойств, о чем неоднократно писали многие исследователи (среди недавних исследований, см., например, работу Н. Г. Архиповой (2000)). Нельзя не отметить значимость того факта, что среди глаголов, употребляющихся с потихоньку, наиболее частотными, по данным языкового корпуса, являются глаголы, выражающие начало действия. Вероятно, в семантической структуре разговорного наречия присутствует компонент, вызывающий такие связи.

В третью группу примеров выделим результаты поиска по англо-русскому корпусу, где в тексте оригинала отсутствует прямое указание на семантику потихоньку. Рассмотрим эти случаи.

В следующем тексте с глаголом double back ‘возвращаться назад (по собственным следам)' нет стимула перевода для наречия потихоньку. Однако так как в контексте предполагается, что вернувшийся герой следит за другим героем, в семантике фразы присутствует некоторая идея секретности.

(13) I didn't say anything to Mum at the time, just said goodbye, then doubled back and followed her to make sure I wasn't imagining things. [Helen Fielding. Bridget Jones's Diary (1996) | Хелен Филдинг. Дневник Бриджит Джонс (А. Москвичева, 2000)].

В тот момент я не стала ничего говорить маме, просто попрощалась и ушла, а затем потихоньку вернулась и стала следить за ней, дабы удостовериться в том, что я ничего не нафантазировала [Хелен Филдинг. Дневник Бриджит Джонс (А. Москвичева, 2000)].

В следующем тексте потихоньку поддерживает значение ‘без скандала', ‘спокойно’:

(14) But he was not above a plan, in which Simpson if not Butler shared, of using political and commercial stoolpigeons to bleed the city treasury as much as possible without creating a scandal [Theodore Dreiser. The Financier (1912)। Теодор Драйзер. Финансист (М. Волосов, 1944)].

Тем не менее его нисколько не покоробил план, придуманный если не Батлером, то Симпсоном: при помощи подставных лиц из политического и коммерческого мира потихоньку, без скандала, выкачать все что можно из городской казны [Теодор Драйзер. Финансист (М. Волосов, 1944)].

Рассмотрим пример:

(15) “Come, come,” said I, “sit up” [Robert Louis Stevenson. Kidnapped (1886) | Роберт Луис Стивенсон. Похищенный (М. Кан, 1967)].

- Ничего-ничего, - сказал я. - Садитесь-ка потихоньку [Роберт Луис Стивенсон. Похищенный (М. Кан, 1967)].

Возможно, форма императива потребовала от переводчика добавления наречия потихоньку для смягчения, а также выражения сочувствия, утешения, стремления успокоить и помочь. Герой, к которому обращается персонаж с предложением сесть, находится в очень плохом состоянии физически и эмоционально (что известно из более широкого контекста), поэтому предложение «Садитесь-ка потихоньку», обращенное к больному и напуганному человеку, выражает, очевидно, намерение успокоить и утешить больного.

Среди примеров нередко встречаются тексты, где стимулом перевода для потихоньку служат глагольные формы с окончанием -ing, которые зачастую в грамматическом значении содержат компонент неспешности протекания действия (при этом этот компонент может присутствовать и в их лексическом значении):

(16) Even though practically everything's airborne these days and most of the tracks are abandoned, the rails are still there, rusting [Ray Bradbury. Fahrenheit 451 (1953) | Рэй Брэдбери. 451 по Фаренгейту (Т. Шинкарь, 1956)].

Все сообщение ведется теперь по воздуху, и большинство железнодорожных путей давно заброшено, но эта колея еще сохранилась, ржавеет потихоньку [Рэй Брэдбери. 451 по Фаренгейту (Т. Шинкарь, 1956)].

Среди примеров перевода встречаются и довольно неожиданные. С одной стороны, можно допустить, что некоторые переводы содержат неточности, и поэтому их не стоит рассматривать. С другой стороны, такие переводы могут демонстрировать языковую интуицию их авторов, и неожиданное употребление наречия потихоньку может расширить понимание семантической природы этого разговорного наречия. 
Например:

(17) I was going to rush by and get away, but a lot of dogs jumped out and went to howling and barking at me, and I knowed better than to move another peg. [Mark Twain. The Adventures of Huckleberry Finn (1884) | Mapk Твен. Приключения Гекльберри Финна (Н. Дарузес, 1950)].

Я хотел было потихоньку пройти мимо и свернуть в сторону, но тут на меня выскочили собаки, завыли и залаяли; и у меня хватило догадки не двигаться с места [Марк Твен. Приключения Гекльберри Финна (Н. Дарузес, 1950)].

Интересен пример с глаголом rush, который имеет значение 'to hurry or move quickly somewhere, or to make someone or something hurry or move quickly somewhere' ('торопить(ся), быстро доставлять'). В оригинальном тексте герой собирается поспешить пройти мимо и скрыться (избежать чего-то / кого-то), а в тексте перевода потихоньку пройти мимо и свернуть в сторону. Получается, что в первом тексте с помощью глагола rush передается значение спешки, быстроты действия, а во втором тексте используется наречие потихоньку (противоположное значению спешки по своей семантике), которое здесь передает значение 'незаметно'.

В следующем примере краткая вопросительная реплика «Потихоньку?», следующая как реакция на фразу «Я взяла вино у отца в комнате», служит переводом для фразы “You didn't steal it” (дословно: Ты его не украла).

(18) She said: "I got it from my father's room". "You didn't steal it". "Not exactly," she said in her careful and precise voice [Graham Greene. The Power and the Glory (1940) | Грэм Грин. Сила и слава (Н. Волжина, 1970-1980)].

Она сказала:

- Я взяла вино у отца в комнате.

- Потихоньку?

- Нет, не совсем, сказала она своим ровным, уверенным голосом [Грэм Грин. Сила и слава (Н. Волжина, 1970-1980)].

В следующем примере наречие потихоньку, вероятно, выражает некоторое смягчение, предположение, которое в английском оригинале выражает словосочетание most likely ('вероятно'). Английское словосочетание выражает модальное значение, при этом в русском тексте перевода используется наречие потихоньку, что говорит о возможном сближении разговорного наречия с модальными словами в сознании носителей языка.

(19) “Take us off to his den and eat us one by one most likely," they muttered. [Clive Staples Lewis. The Chronicles of Narnia. Prince Caspian (1951) | Клайв Стейплз Льюис. Хроники Нарнии. Принц Каспиан (Г. А. Островская, 1991)].

«Заберет нас отсюда в свое логово и съест потихоньку одного за другим», - бормотали они [Клайв Стейплз Льюис. Хроники Нарнии. Принц Каспиан (Г. А. Островская, 1991)].

Среди факторов, указывающих на лингвоспецифичность лексической единицы, Анна А. Зализняк отмечает частотность замены части речи при переводе, большое количество имеющих приблизительно равную частотность стимулов перевода, неоднословность стимулов перевода, большой процент случаев, когда в иностранном оригинале вообще отсутствует какая-либо единица-стимул, которую можно было бы сопоставить анализируемой русской лексической единице и др. (Зализняк, 2015, с. 687-688). По данным показателям наречие потихоньку обладает некоторой степенью лингвоспецифичности.

Как показал анализ текстов англо-русского корпуса, при переводе часто происходит замена части речи. В качестве стимулов перевода выступают наречия, прилагательные, местоимения, глаголы, а также словосочетания и фразы (подробный анализ примеров с наречиями и прилагательными см. в первой части исследования). Во многих примерах в иностранном оригинале отсутствует какая-либо единица, которую можно было бы считать стимулом перевода.

Анализ данных русско-английского параллельного корпуса также показал, что среди переводных текстов встречаются слова разных частей речи, которые можно сопоставить с потихоньку. Наречия: quietly, slowly, cautiously, gently, stealthily, gradually, silently, secretly, softly, furtively. Прилагательные: furtive, secret. Глаголы, которые послужили переводом для русских глаголов в сочетании с потихоньку: slip away, steal, whisper, venture. Неоднословные единицы: by stealth, on the sly, perhaps just, little by little, more and more, in secret, by easy stages. Видно, что многие единицы из данного списка совпадают с данными англо-русского корпуса, а также подтверждают выводы, сделанные на основании анализа англо-русских переводов. Так, появление слов perhaps just ('возможно просто') также указывает на роль смягчения, которую выполняет диминутив потихоньку. В русско-английских переводах также встречаются многочисленные случаи, когда в оригинальном тексте отсутствуют лексические единицы, которые можно сопоставить слову потихоньку.

Кроме того, в текстах русско-английского корпуса (это в основном тексты русской классической литературы) представлена целая серия примеров, где наречие потихоньку переводится описательно. Все их объединяет значение секрета, тайны, и наречие часто употребляется в сочетании с наименованием лица, в тайне от которого совершается действие (потихоньку от кого):

(20) Подходя, он вспомнил, что отец очень настаивал накануне, чтоб он как-нибудь вошел потихоньку от брата Ивана [Ф. М. Достоевский. Братья Карамазовы (ч. 1-2) (1878)].

On the way he remembered that his father had insisted the day before that he should come without his brother Ivan seeing him [Fedor Dostoevsky. The Brothers Karamazov (parts 1-2) (Constance Garnett, 1912)].

(21) Левин шел подле жены, виновато за свою досаду, потихоньку от няни, пожимая ее руку [Л. Н. Толстой. Анна Каренина (ч. 5-8) (1878)].

Levin walked beside his wife, and, penitent for having been angry, he squeezed her hand when the nurse was not looking [Leo Tolstoy. Anna Karenina (parts 5-8) (Constance Garnett, 1911)]. 


\section{Заключение}

Резюмируя анализ корпусных данных, можно сделать следующие выводы. Было выявлено, во-первых, частотное употребление потихоньку с глаголами движения при переводе английских фразовых глаголов движения и перемещения с различными оттенками. Во-вторых, участие потихоньку в переводах глагольных форм с окончанием -ing, что показывает взаимосвязь с семантикой процесса, неспешности действия не только на уровне лексического значения, но и на уровне грамматического значения. В-третьих, выявлена особая взаимосвязь семантики потихоньку с семантическим признаком начала действия, которая проявляется в сочетаемостных характеристиках данного слова, по данным и параллельного корпуса, и основного корпуса русского языка. В-четвертых, среди переводов частотны тексты, когда в английском оригинале отсутствует какая-либо лексическая единица, которую можно было бы сопоставить наречию потихоньку в тексте перевода, где потихоньку может передавать различные дополнительные оттенки.

Итак, подводя итоги проведенного исследования, можно отметить следующее. Исходя из критериев лингвоспецифичности лексической единицы, выделенных Анной А. Зализняк, диминутив потихоньку можно отнести к лингвоспецифичным единицам. Во многом это можно объяснить широким спектром контекстуальных значений наречия потихоньку, его сложной семантической природой, для которой характерно тяготение к диффузности, появление прагматических коннотаций.

Перспективы дальнейшего исследования проблемы видятся в дальнейшем изучении лингвоспецифичности диминутивных слов русского языка, в выявлении их общих черт и характерных особенностей.

\section{Источники | References}

1. Архипова Н. Г. Сочетаемость слова в лексикографическом описании: дисс. ... к. филол. н. М., 2000.

2. Воейкова М. Д. Структурные функции диминутивов в современном русском языке и продуктивность их употребления // Вопросы языкознания. 2020. № 5.

3. Девкин В. Д. Немецкая разговорная речь. Синтаксис и лексика. М.: Международные отношения, 1979.

4. Зализняк А. А. Лингвоспецифичные единицы русского языка в свете контрастивного корпусного анализа // По материалам ежегодной Международной конференции «Диалог» (г. Москва, 27-30 мая 2015 г.). М.: Изд-во РГГУ, 2015. Вып. 14 (21): в 2-х т. Т. 1. Основная программа конференции.

5. Кембриджский словарь. 2021. URL: https://dictionary.cambridge.org/ru/

6. Национальный корпус русского языка. 2021. URL: https://ruscorpora.ru/old/

7. Николина Н. А. Функционирование диминутивов в современной русской речи // Русский язык в школе. 2020. № 81 (5).

8. Скребнев Ю. М. Введение в коллоквиалистику / под ред. О. Б. Сиротининой. Саратов: Изд-во Сарат. ун-та, 1985.

9. Фуфаева И. В. Экспрессивные диминутивы в условиях конкуренции с нейтральными существительными (на материале русского языка): дисс. ... к. филол. н. М., 2017.

10. Харченко В. К. Антология разговорной речи: некоторые аспекты теории: в 5-ти т. М.: URSS, 2016. T. 1. Aграмматизмы - Креация.

11. Чевардина Л. В. Обучение иностранных студентов экспрессивным средствам русской речи на примере суффиксов субъективной оценки // Журнал педагогических исследований. 2018. № 4.

12. Шлыкова Л. А., Эльвия В. Методика обучения диминутивам на занятиях по русскому языку как иностранному // Научный вестник Воронежского государственного архитектурно-строительного университета. 2012. № 8.

13. Шмелев А. Д. Русские лингвоспецифичные лексические единицы в параллельных корпусах: возможности исследования и «подводные камни» // Компьютерная лингвистика и интеллектуальные технологии: по материалам ежегодной Международной конференции «Диалог» (г. Москва, 27-30 мая 2015 г.). М.: Изд-во РГгу, 2015. Вып. 14 (21): в 2-х т. Т. 1. Основная программа конференции.

\section{Информация об авторах | Author information}

RU Сидорова Елена Юрьевна ${ }^{1}$, к. филол. н.

${ }^{1}$ Российский государственный педагогический университет имени А. И. Герцена, г. Санкт-Петербург

EN Sidorova Elena Yurievna ${ }^{1}, \mathrm{PhD}$

${ }^{1}$ Herzen State Pedagogical University of Russia, Saint Petersburg

${ }^{1}$ blueberry_nights@list.ru

\section{Информация о статье | About this article}

Дата поступления рукописи (received): 12.10.2021; опубликовано (published): 30.11.2021.

Ключевые слова (keywords): диминутив; корпус; параллельный корпус; семантика; diminutive; corpus; parallel corpus; semantics. 